\title{
Analysis of Contamination in Nanoscaled Film Structures with TEM \& XPS
}

\author{
Q. J. Huang, K. M. Paing, and C. M. Lilley*
}

*Department of Mechanical and Industrial Engineering, University of Illinois at Chicago

2039 Engineering Research Facility, 842 W. Taylor Street (MC 251), Chicago, IL 60607 USA

Contamination plays an important role for nanotechnology and nanodevices. As a component size decreases to the nanoscale, even small percentages of contaminants can significantly alter electrical, thermal, and mechanical properties [1]. Thus, functionality, performance, and quality are affected. One issue that should be investigated is whether significant contamination is present in nanoscaled materials fabricated with high purity sources in a Class 1000 cleanroom. Typically, contamination of structural materials for micro- or nanodevices is not considered nor discussed. In this paper, TEM (Transmission Electron Microscopy) and XPS (X-ray Photoemission Spectroscopy) analysis was performed on $\mathrm{Au} / \mathrm{Cr} / \mathrm{SiN} / \mathrm{Si}$ film to determine whether contaminant is present and the concentration.

A SiN layer was deposited on a 3" Si wafer with low-pressure chemical vapor deposition at $800{ }^{\circ} \mathrm{C}$. The gold and chrome layers were deposited by e-beam evaporation with high purity (99.99\%) sources during a single run. As shown in Fig. 1, the microstructures for the $\mathrm{Au} / \mathrm{Cr} / \mathrm{SiN} / \mathrm{Si}$ layers are clearly visible in the TEM images. A metal polycrystalline structure was found in the gold layer with a $\sim 195 \mathrm{~nm}$ thickness. The thickness of the metal polycrystalline chromium layer is about $8 \mathrm{~nm}$. The chrome is an adhesion layer for the gold to adhere to the substrate. The SiN layer is an amorphous structure with a thickness of $\sim 350 \mathrm{~nm}$. The single-crystal ordered structure of the $<100>\mathrm{Si}$ is also clearly visible. With x-ray spectroscopy (XEDS), we found $\mathrm{C}$ and $\mathrm{O}$ to be present in all layers of the specimen. Further analysis with Electron Energy Loss Spectroscopy (EELS) was conducted to measure the composition of the layers and the atomic ratios for $\mathrm{C}, \mathrm{O}, \mathrm{N}$, as shown in Table 1. Quantification of C and O content of gold layer was not possible.

A second analysis was conducted with XPS using an AXIS-165 surface analysis system. A second sample, $\sim 4 \mathrm{~mm} \times 4 \mathrm{~mm}$, was cut from the original die and the analysis was started from the gold layer (top surface of the film). The system was operated with a chamber vacuum of $9.0 \times 10^{-9}$ Torr. Fig. 2 shows the XPS survey scan for the top gold surface. Detailed measurements of the O 1s, C 1s and Si 2s peaks were carried out with multiplex scans using steps of $0.1 \mathrm{eV}$, as shown in the insets of Fig. 2 . The scan indicates $\mathrm{C}, \mathrm{O}$ and $\mathrm{Si}$ contamination in this area from exposure to environmental conditions. However, as the ion gun etched the sample, $\mathrm{C}$ and $\mathrm{O}$ contaminants were still present in measurable concentrations. The atomic concentrations of different depths are outlined in Table 2.

Carbon contamination is common in cross sectional TEM analysis since we use hydrocarbon glue and organic solvents when preparing the sample. The presence of oxygen from the EELS result could also be explained by sample exposure to air. However, the presence of $\mathrm{C}$ and $\mathrm{O}$ were confirmed with the XPS analysis in all layers of the specimen although they were fabricated with high purity sources in a cleanroom. The presence of contaminants can be a result of residues from previous depositions, exposure to air, and handling of components for the chambers and sources.

[1] D. P. Ames and S. J. Chelli, Surface \& Coatings Technology, 187 (2004) 199 


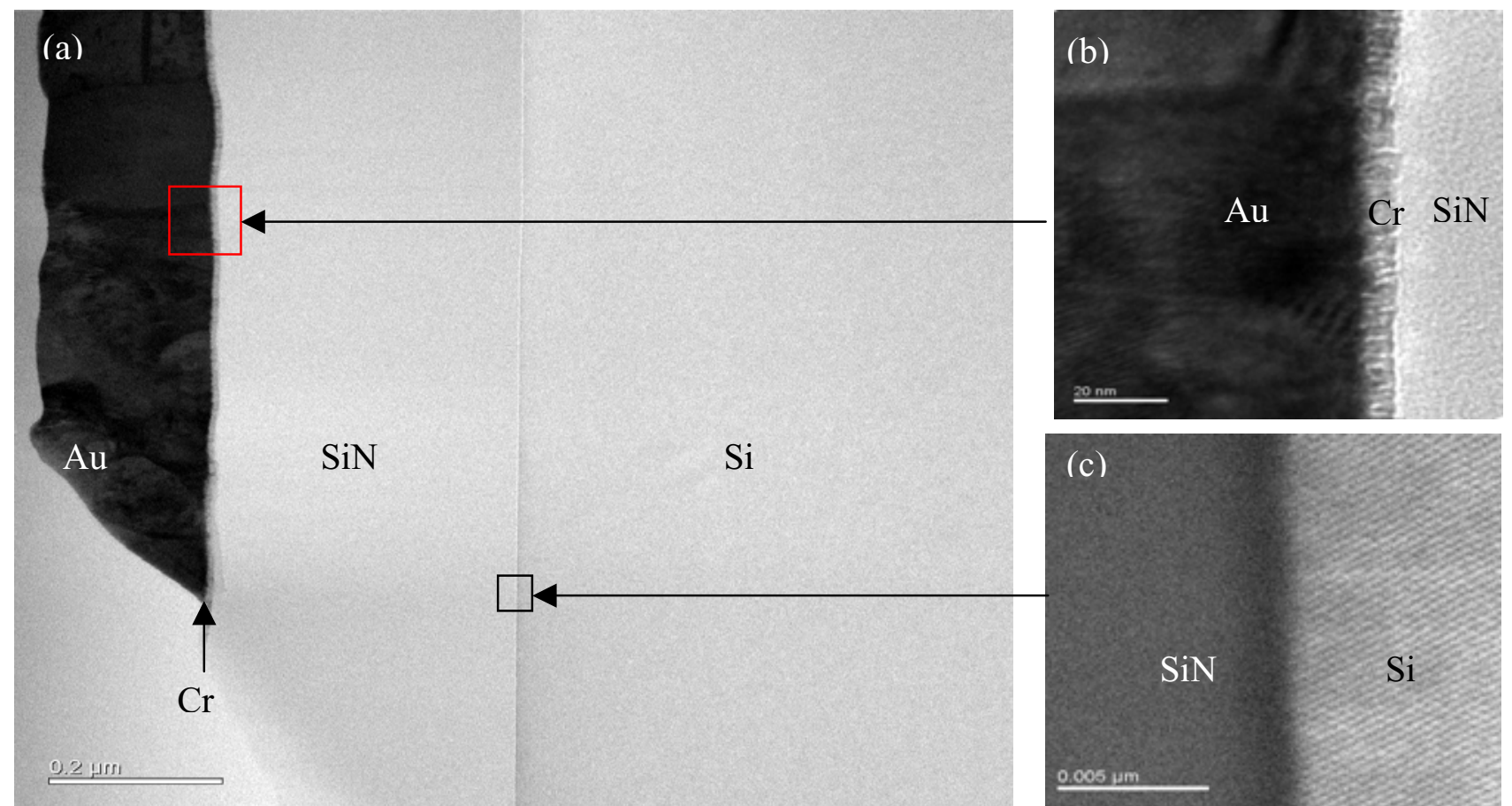

Figure 1. The cross-section TEM images: (a) low magnification BF STEM image of all layers; (b) high magnification view of $\mathrm{Au}, \mathrm{Cr}$ and $\mathrm{SiN}$ layers; (c) high magnification $\mathrm{Z}$ contrast STEM image of $\mathrm{SiN}$ and Si layers.

Table 1. C, $\mathrm{N}$ and $\mathrm{O}$ ratios from EELS

\begin{tabular}{cccc}
\hline Elements & $\begin{array}{c}\mathrm{Au} \\
\text { layer }\end{array}$ & $\begin{array}{c}\mathrm{Cr} \\
\text { layer }\end{array}$ & $\begin{array}{c}\mathrm{SiN} \\
\text { layer }\end{array}$ \\
\hline $\mathrm{C}$ & Present & 1.0 & 0.12 \\
$\mathrm{~N}$ & 0 & 0 & 1.0 \\
$\mathrm{O}$ & Present & 0.17 & 0.08 \\
\hline
\end{tabular}
Table 2. Atomic concentration (\%) from XPS Top Au Middle Bottom Top SiN Middle

\begin{tabular}{cccccc} 
& area & $\mathrm{Au}$ area & $\mathrm{Au}$ area & area & $\mathrm{SiN}$ area \\
\hline $\mathrm{C}$ & 41.16 & 13.09 & 5.08 & 4.43 & 4.43 \\
$\mathrm{O}$ & 19.39 & 4.49 & 1.24 & 4.24 & 5.04 \\
$\mathrm{Cr}$ & 0.00 & 0.00 & 0.00 & 15.09 & 6.05 \\
$\mathrm{Si}$ & 17.63 & 13.95 & 8.39 & 20.31 & 36.42 \\
$\mathrm{~N}$ & 1.86 & 4.60 & 5.38 & 27.17 & 41.56 \\
$\mathrm{Au}$ & 19.99 & 63.87 & 79.91 & 28.77 & 6.49 \\
\hline
\end{tabular}

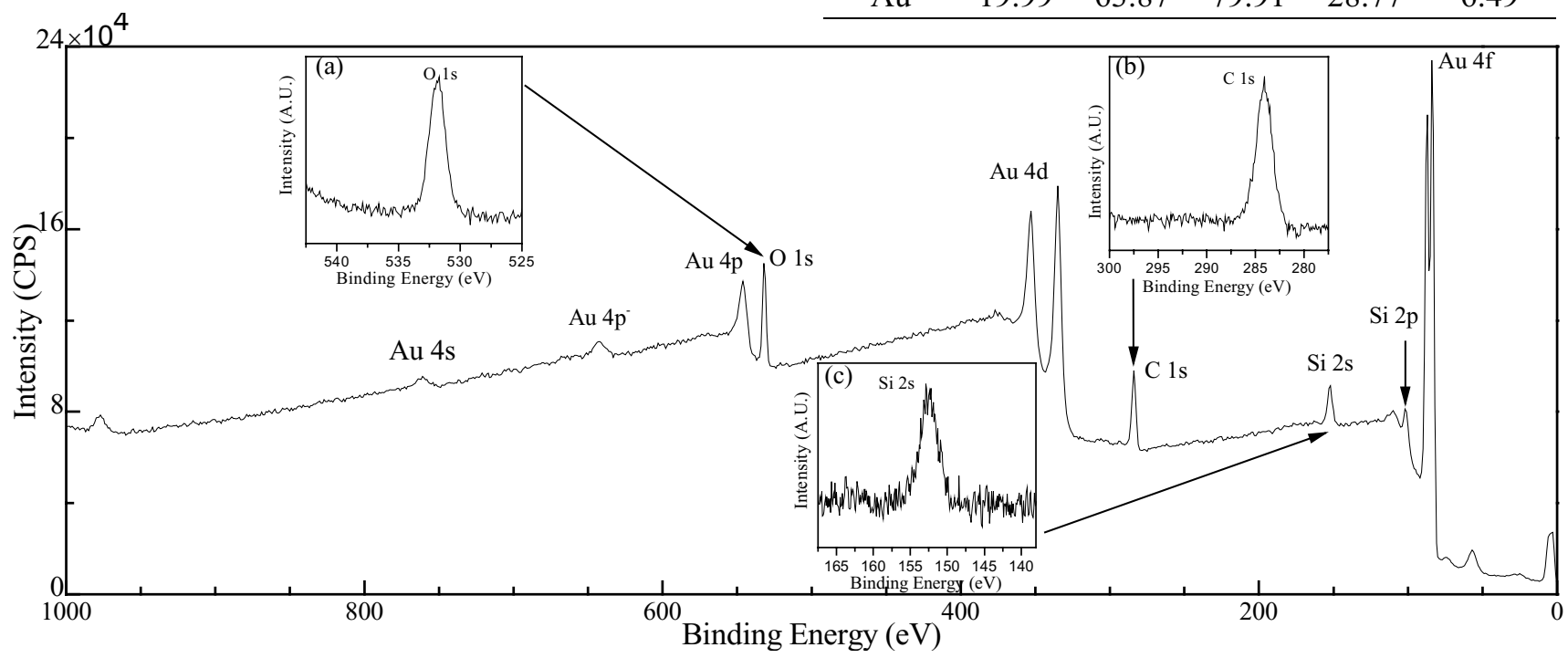

Figure 2. XPS survey scans for the top gold surface of the $\mathrm{Au} / \mathrm{Cr} / \mathrm{SiN} / \mathrm{Si}$ specimen: the insets are multiplex scans with high resolution of (a) Oxygen 1s, (b) Carbon 1s and (c) Si 2s, respectively. 